\title{
Two-dimensional Modelling of Thermal Responses of GFRP Profiles Exposed to ISO-834 Fire
}

\author{
Teng Ding ${ }^{1}$, Lu Wang ${ }^{1, *}$, Weiqing Liu ${ }^{1}$ \\ ${ }^{1}$ College of Civil Engineering, Nanjing Tech University, 211816 Nanjing, China
}

\begin{abstract}
In the past three decades, one-dimensional (1-D) thermal model was usually used to estimate the thermal responses of glass fiber-reinforced polymer (GFRP) materials and structures. However, the temperature gradient and mechanical degradation of whole cross sections cannot be accurately evaluated. To address this issue, a two-dimensional (2-D) thermo-mechanical model was developed predict the thermal and mechanical responses of rectangular GFRP tubes subjected to one-side ISO-834 fire exposure in this paper. The 2-D governing heat transfer equations with thermal boundary conditions, discretized by alternating direction implicit (ADI) method, were solved by Gauss-Seidel iterative approach. Then the temperature-dependent mechanical responses were obtained by considering the elastic modulus degradation from glass transition and decomposition of resin. The temperatures of available experimental results can be reasonably predicted. This model can also be extended to simulate the thermo-mechanical responses of beams and columns subjected to multi-side fire loading, which may occur in real fire scenarios.
\end{abstract}

\section{INTRODUCTION}

In the past two decades, a large number of experimental studies have been conducted to evaluate the thermal and thermo-mechanical performances of FRP materials [1-7]. In 1999, the fire resistance of GFRP sprinkler pipes with empty cavity, stagnant water and flowing water were investigated by Davies and Dewhurst [8]. The failure time of the pipes with empty cavity and stagnant water were $1.5 \mathrm{~min}$ and 8.5 min, respectively, while the flowing water-cooled pipe remained structural integrity subjected to $120 \mathrm{~min}$ fire exposure. Inspired by the water-cooling concept of filament wound GFRP pipe used in [8], this concept, developed by Keller, was applied in the fire endurance of pultruded GFRP multi-cellular panels $[9,10]$. The fire performance of GFRP panels were investigated in three different experimental parts: charring of GFRP laminates, fire endurance of liquid cooling moderately-sized GFRP panels and fire resistance of structural liquid cooling full-scale GFRP panels, respectively. In the first part, the pultruded GFRP laminates started burning at roughly $6 \mathrm{~min}$, and the temperature of cold face reached the $\mathrm{Tg}$ at approximately $10 \mathrm{~min}$ [11]. In the second part, the temperature profiles through the thickness of lower face sheet were much lower than those of charring experiments[9]. In the third part, for the non-cooled specimens, the cold face of lower face sheet reached $\mathrm{Tg}$ and Td in $10 \mathrm{~min}$ and $57 \mathrm{~min}$, respectively. The test results demonstrated that liquid-cooling was an effective way to improve the fire resistance of pultruded GFRP components. The non-cooled column failed at $49 \mathrm{~min}$ due to global buckling, while structural function of the water cooled columns could be maintained for two hours. In 2010, the fire resistances of non-cooled and water-cooled pultruded GFRP beams with square hollow section were investigated by Correia et al [12]. The bottom flange of the GFRP beams were subjected to ISO-834 fire. The fire resistance was over $120 \mathrm{~min}$ by using the water-cooled approach with a $72 \mathrm{~mm} / \mathrm{s}$ flowing rate. But the non-cooled specimen failed abruptly after about $38 \mathrm{~min}$ due to the kinking and buckling of top flange.

The mathematical modeling of the thermal response of FRP composite under elevated and high temperatures has been proposed. In 2006, the apparent specific capacity, developed by Lattimer [13], was input into a heat transfer model to predict the temperature profile through E-glass/vinyl ester composite laminates. Gibson et al. [14, 15] investigated the post-fire mechanical properties of polymer composites by combing the thermal model with

\footnotetext{
* Corresponding author: kevinlwang@njtech.edu.cn
} 
Mouritz's two-layer mechanical model [16]. In 2012, the thermal responses of FRP laminates subjected to three-point bending and one-side heat flux were experimental and numerical investigated by Gibson et al. [17]. Feih et al. $[18,19]$ presented the thermo-mechanical model to predict the tension and compression properties of FRP laminates in fire. A 1-D model was further developed to simulate the thermo-mechanical responses of sandwich composites [20]. This model also validated and applied by Anjiang et al. [21, $22]$ to investigate the in-fire and post-fire mechanical properties of FRP sandwich composite structures with balsa wood core. In 2006, a thermo-chemical and thermo mechanical models were introduced by Keller [23]. The models were used to predict the structural response of water-cooled multi-cellular GFRP slabs. In 2007, Bai and Keller [24] proposed the chemical kinetics-based thermo-physical model by considering the decomposition of matrix resin. Based on the temperature-dependent thermo-physical model, an 1-D thermal model with the effective specific capacity was developed [25]. More recently, a 3-D FE model was developed by Shi et al. [26] to investigate the coupled temperature-diffusion-deformation problem of silica/phenolic composite materials. The accuracy of this model was validated by comparing the measured temperatures and displacements with numerical results.

Among the various existing thermal models, the 1-D finite difference method was most frequently used to predict the thermal response of FRP composites. However, the FRP structural components applied in building construction were subjected to multi-dimensional fire exposures. The temperature profile of heated zone of FRP composites cannot be predicted by the use of 1-D model. Hence, to address this issue, a 2-D thermal model was proposed in this study. The accuracy of the proposed model was validated by the existing experimental data of pultruded E-glass/polyester rectangular tube under fire from one side. The comparison indicated that the developed two-dimensional thermal model can be reasonable to predict the thermal responses of GFRP composites.

\section{MATHEMATICAL MODEL}

\subsection{Modeling assumptions}

When subjected to fire, FRP composites undergo many complex thermal, physical, chemical and structural failure processes. The challenge to accurately modeling the temperature responses is to consider complex interaction of degradation processes. Previous studies [11,25] showed that the thermal and mechanical processes were dominated by glass transition and thermal decomposition. The convective heat transfer of volatiles flow up through the decomposition front to the surface may have a small effect on the temperature profile in the FRP material[14]. Hence, in this study, the 2-D thermo-mechanical model was simplified by considering heat conduction, physical process (glass transition), chemical (decomposition) and mechanical degradations.

\subsection{Thermo-physical properties model}

During fire processes, thermo-physical properties include density, specific capacity and thermal conductivity of virgin (non-char) and char material.

A lot of works were made to investigate these properties. The temperature-dependent density can be described by using an Arrhenius equation based on chemical kinetics [26]:

$$
\frac{\partial \rho}{\partial t}=-A \rho \exp \left(\frac{-E_{A}}{R T}\right)
$$

where $\rho$ is the density; A represents the pre-exponential factor; $E_{A}$ is the activation energy; $\mathrm{R}$ is the universal gas constant; and $\mathrm{T}$ is temperature.

The change of density can be described by Eq. (1). But in the existing literatures, specific capacity and thermal conductivity of virgin and char were usually expressed by polynomial fitting instead of analytical from. Hence, the parameters used in fitting have no clear physical meaning. Bai et al. [26] developed a model for predicting temperature-dependent thermo-

physical properties. In this model, a conversion degree of decomposition was introduced to characterize the pyrolysis process of polymer resin, as indicated in Eq. (2).

$$
\frac{d \alpha_{d}}{d t}=A_{d} \exp \left(\frac{-E_{A, d}}{R T}\right)\left(1-\alpha_{d}\right)^{n r_{d}}
$$

where $\alpha \mathrm{d}$ denotes the decomposition degree, $A_{d}, E_{A, d}, n r_{d}$ are kinetic parameters, which can be derived from thermo-gravimetric analysis.

Based on decomposition degree $\alpha \mathrm{d}$, the temperature-dependent density can be obtained,

$$
\rho=\left(1-\alpha_{d}\right) \rho_{b}+\alpha_{d} \rho_{a}
$$

where $\rho_{b}$ is the density of virgin composite, and $\rho_{a}$ is the density of char material.

The apparent specific capacity can be given as [26]

$$
C_{p}=f_{b} C_{p b}+\left(1-f_{b}\right) C_{p a}+\frac{d \alpha_{d}}{d T} C_{d}
$$

where $C_{p}$ is the apparent specific capacity, which increases due to endothermic phenomenon during decomposition process [27]; $C_{p, b}$ and $C_{p, a}$ are apparent specific capacity before and after decomposition respectively; $C_{d}$ is decomposition heat; and $f_{b}$ is mass fraction of un-decomposed FRP materials, which can be calculated by Eq. (5).

$$
f_{b}=\frac{M_{a, v}\left(1-\alpha_{d}\right)}{M_{a, v}\left(1-\alpha_{d}\right)+M_{a, e} \alpha_{d}}
$$

where $M_{a, v}\left(M_{a, e}\right)$ is the initial(final) mass of FRP material.

In this paper the main research object is the cross section of rectangular GFRP tubes, only the cross sectional properties should be considered. Previous study showed that thermal conductivity parallel to the axis of fiber $(00)$ was much higher than in the transverse (90o) and through thickness direction, while the thermal conductivity of transverse and through thickness direction were similar for glass fiber/polyester composites. Hence, the transverse thermal conductivity can be simplified by using the through thickness thermal conductivity. The thermal conductivity 
through the thickness of FRP composites can be expressed as [26]

$$
\frac{1}{k_{\perp}}=\frac{\left(1-\alpha_{d}\right)}{k_{\perp b}}+\frac{\alpha_{d}}{k_{\perp a}}
$$

where $k_{\perp}$ denotes the through thickness thermal conductivity; the subscripts $b$ and a represents the thermal conductivity before and after decomposition, respectively; and $k_{\perp_{b}}$ and $k_{\perp}$ ${ }_{a}$ can be obtained by using the inverse rule of mixtures.

$$
\begin{gathered}
\frac{1}{k_{\perp b}}=\frac{V_{f}}{k_{f}}+\frac{V_{m}}{k_{m}} \\
\frac{1}{k_{\perp a}}=\frac{V_{f}}{k_{f}}+\frac{V_{g a}}{k_{g a}}
\end{gathered}
$$

where $k_{f}, k_{m}$ and $k_{g a}$ are the thermal conductivities of fiber, matrix and volatile gas, respectively; $V_{f}, V_{m}$ and $V_{g a}$ are the volume fractions of fiber, matrix and volatile gas, respectively.

\subsection{2-D Heat transfer model}

2-D transient heat transfer equation can be expressed as

$$
\rho C_{p} \frac{\partial T}{\partial t}=\frac{\partial}{\partial x}\left(k_{x} \frac{\partial T}{\partial x}\right)+\frac{\partial}{\partial y}\left(k_{y} \frac{\partial T}{\partial y}\right)
$$

where $\mathrm{kx}$ and $\mathrm{ky}$ are the thermal conductivity in $\mathrm{x}$ and $\mathrm{y}$ directions, respectively. The term on the left side of Eq. (9) refers to the rate of change of internal energy, and the other two terms on the right side denote the net heat flux.

The boundary conditions applied in thermal analysis can be divided into three types. The first one is the Dirichlet boundary condition, which can be expressed as

$$
\left.T(x, y, t)\right|_{b d}=T(t)
$$

where $k_{x}$ and $k_{y}$ represent the 2-D spatial Descartes coordinates; Subscript bd denotes the boundaries of rectangular tube; and $\mathrm{T}(\mathrm{t})$ is the time-dependent specific temperature on the boundary. The second one is the prescribed heat flux, which can be expressed as

$$
\begin{aligned}
& -\left.k_{x} \frac{\partial T(x, y, t)}{\partial x}\right|_{b d}=q(t) \\
& -\left.k_{y} \frac{\partial T(x, y, t)}{\partial y}\right|_{b d}=q(t)
\end{aligned}
$$

where $\mathrm{q}(\mathrm{t})$ is the time-dependent heat flux at the boundaries. The last one is the convection between the boundary and external environment, which can be expressed as

$$
\begin{aligned}
& -\left.k_{x} \frac{\partial T(x, y, t)}{\partial x}\right|_{b d}=h\left(T_{\infty}(t)-\left.T(x, y, t)\right|_{b d}\right) \\
& -\left.k_{y} \frac{\partial T(x, y, t)}{\partial y}\right|_{b d}=h\left(T_{\infty}(t)-\left.T(x, y, t)\right|_{b d}\right)
\end{aligned}
$$

where $\mathrm{h}$ denotes the convective coefficients, and $T_{\infty}(\mathrm{t})$ represents the time-dependent temperature of external environment.

In this study, convection and radiation between the boundaries and external/internal environment can be obtained
$q(t)=h_{x}\left[T_{\infty}(t)-\left.T(x, y, t)\right|_{b d}\right]+\varepsilon_{x, r} \sigma_{x, r}\left[T_{\infty}(t)^{4}-\left.T(x, y, t)^{4}\right|_{b d}\right]$

$$
q(t)=h_{y}\left[T_{\infty}(t)-\left.T(x, y, t)\right|_{b d}\right]+\varepsilon_{y, r} \sigma_{y, r}\left[T_{\infty}(t)^{4}-\left.T(x, y, t)^{4}\right|_{b d}\right]
$$

\section{VALIDATION}

\subsection{Basic model}

As described in Section 1, Correia et al. [12] conducted the fire structural experiment of pultruded E-glass/polyester composite square beam subjected to ISO-834 fire, and a 37 min fire resistance was reached. In this paper, this experiment is used to validate the proposed 2-D numerical model. The heat convective coefficients at the cold face of bottom flange were estimated as $2 \mathrm{~W} / \mathrm{m} 2 \mathrm{~K}$ by fitting the temperature profiles at the cold face of the bottom flange [28].

\subsection{Validation and comparison}

Fig. 2 shows the 2-D modelling and experimental temperatures through the thickness of GFRP bottom flange. Reasonable agreement was found, especially in the first 5 min and last $20 \mathrm{~min}$. some fluctuations can be seen after 5 min fire exposure due to the jump of the oven temperature. The 2- D temperature gradients at $5 \mathrm{~min}, 10 \mathrm{~min}, 20 \mathrm{~min}$ and $40 \mathrm{~min}$ were presented in Fig. 2. A large temperature gradient through the thickness of bottom flange was found at $5 \mathrm{~min}$ and $10 \mathrm{~min}$, however, the gradient decreased from 10 $\min$ to $40 \mathrm{~min}$. This indicated that a more even temperature distribution was found through the thickness of bottom flange, and the temperatures of hot face and inner face were approximately $750 \mathrm{C}^{\circ}$ and $900 \mathrm{C}^{\circ}$ at $40 \mathrm{~min}$.

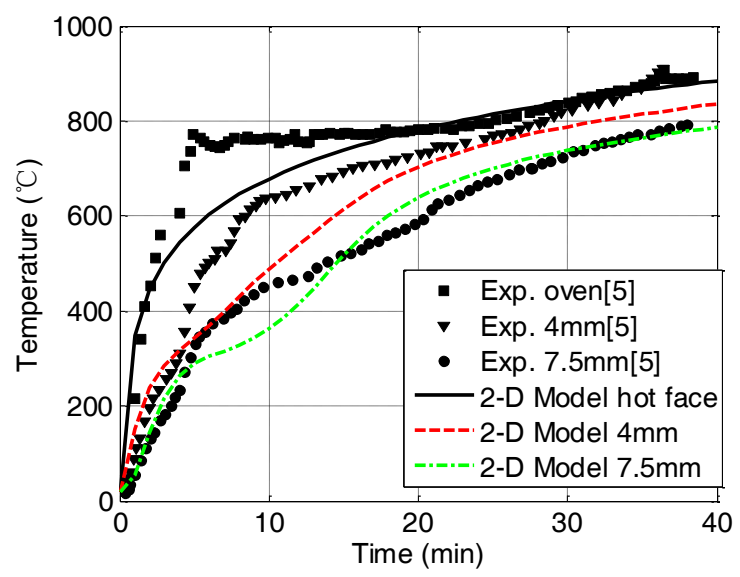

Fig. 1 Model validation by temperature comparison 


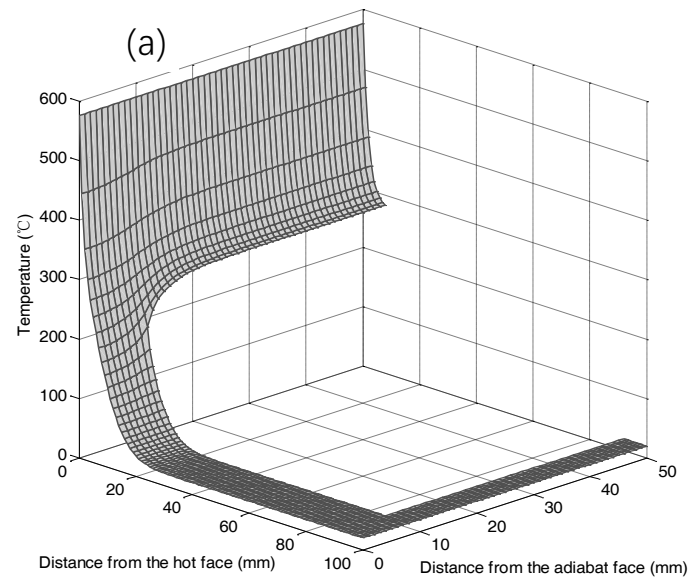

(b)
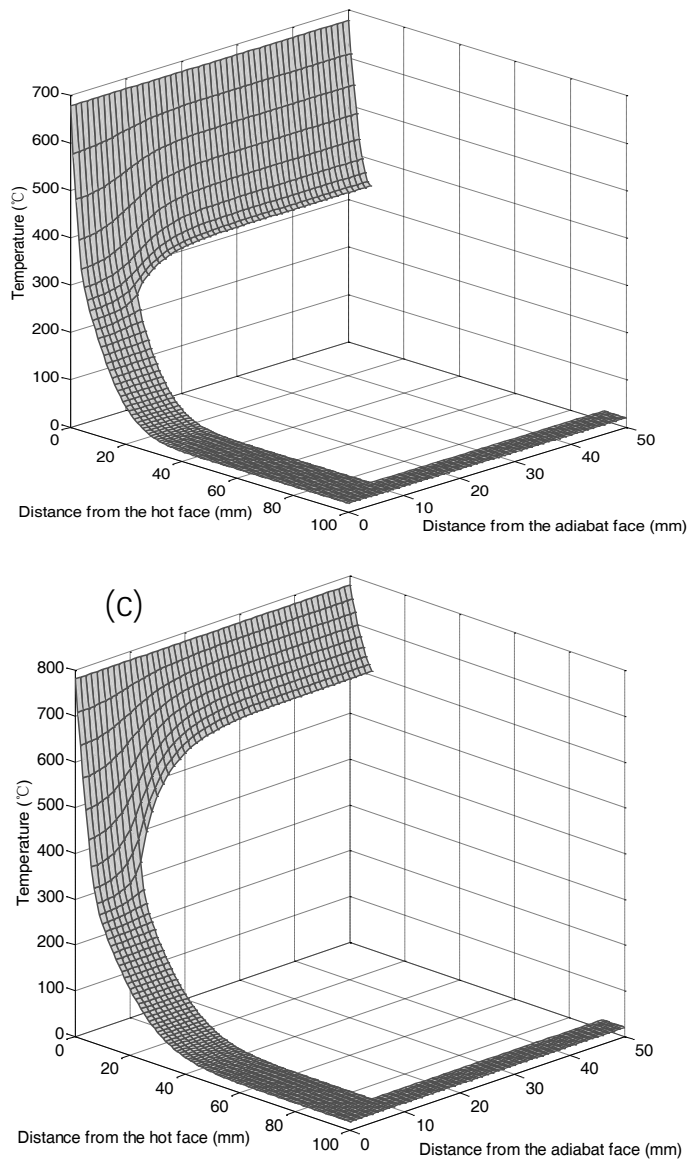

(d)

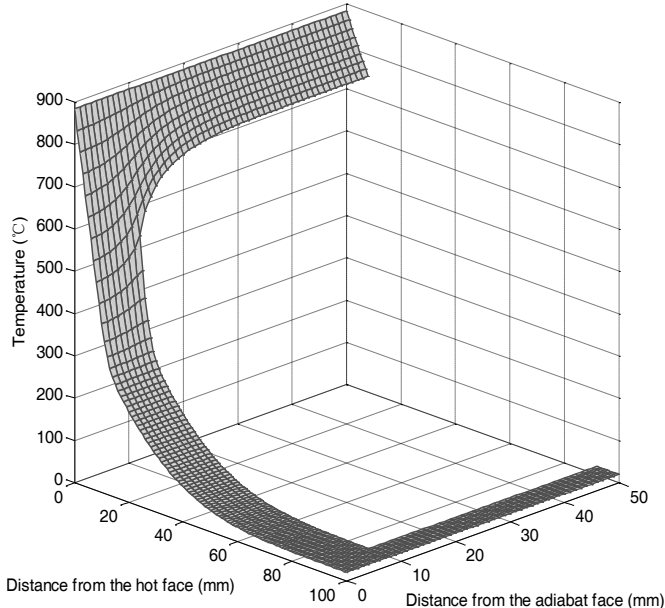

Fig. 2 Temperature distribution of GFRP tube: (a) $5 \mathrm{~min}$, (b) 10 min, (c) 20 min, (d) 40 min.

\section{CONCLUSIONS}

In this study, a 2-D model to predict the thermal responses of rectangular GFRP tubes were developed and solved by ADI finite difference scheme. The modeling results were compared with the temperature from experiment on GFRP rectangular beam under one-side fire exposure. The main conclusion remarks were drawn:

(1) A 2-D thermo-mechanical model based on finite difference method was developed and solved by Gauss-Seidel iterative approach. The detailed ADI schemes considering complex boundary conditions were also presented, and the numerical results were stable due to the stability of this difference format.

(2) The proposed 2-D thermal model can reasonably predict the temperatures of GFRP rectangular tube. Based on the calculated temperature, the temperature-dependent conversion degree of glass transition and decomposition as well as thermo-physical properties of the whole cross-section can also be obtained.

\section{ACKNOWLEDGEMENT}

The work described here was supported by the National key research and development program of China (Grant No. 2017YFC0703001) and the National Natural Science Foundation of China (Grant No. 51678297).

\section{References}

1.Wu Q, Yang FY, Sun GQ, Liu WQ, Wang L (2018). Analytical method for determination of temperature-induced interfacial shear stress in foam-core composite sandwich materials. Plastics, Rubber and Composites, 47(5) . pp 232-239.

2. Wang L,Wu ZM, Liu WQ, Wan L (2018). Structural behavior of load-bearing sandwich wall panels with GFRP skins and a foam-web core. Science and Engineering of Composite Materials, 25(1) . pp 173-188.

3. Zhang LF, Liu WQ, Sun GQ, Wang L, Li LZ (2018). Two-dimensional Modeling of Thermo-mechanical Responses of Rectangular GFRP Profiles Exposed to Fire. Advances in Materials Science and Engineering, 1705915. 4. Xia YW, Li XP, Peng Y, Lai MH, Wang L (2018). Impact and Post-Impact Performance of Sandwich Wall Boards with GFRP Face Sheets and a Web-Foam Core: The Effects of Impact Location. Materials, 11, 1714.

5. Wang XK, Ma YL, Liu WQ, Liang RF, Wang L(2018). Mode I interfacial fracture characterization of foam core sandwich materials at elevated temperatures. Journal of Reinforced Plastics and Composites, 36(14) . pp 1009-1018. 6. Fang Y, Wang K, Hui D, Xu FJ, Liu WQ, Yang SL, Wang L (2017). Monitoring of seawater immersion degradation in 
glass fibre reinforced polymer composites using quantum dots. Composites Part B, 112. pp 93-102.

7. Wang L, Fan XM, Chen H, Liu WQ (2016). Axial crush behavior and energy absorption capability of foam-filled GFRP tubes under elevated and high temperature. Composite structures,149. pp 339-350.

8.Davies JM, Dewhurst DW (1999). The fire performance of GRP pipes in empty and dry, stagnant water filled and flowing water filled conditions. Composites in Fire. Proceedings of the International Conference on the Response of Composite Materials. Newcastle upon Tyne, 1999. pp. 69-84.

9. Keller Thomas, Zhou Aixi, Tracy Craig, Hugi Erich, Schnewlin Peter (2005). Experimental study on the concept of liquid cooling for improving fire resistance of FRP structures for construction. Composites Part A, 36(11). pp 1569-1580.

10. Keller Thomas, Tracy Craig, Hugi Erich (2006). Fire endurance of loaded and liquid-cooled GFRP slabs for construction. Composites Part A, 37(7).pp 1055-1067.

11. Tracy Craig(2005). Fire endurance of multicellular panels in an FRP building system. Ph.D. Thesis No. 3235, EPFL-CCLab.

12. Correia JR, Branco FA, Ferreira JG, Bai Yu, Keller Thomas (2010). Fire protection systems for building floors made of pultruded GFRP profiles: Part 1: Experimental investigations. Composites Part B, 41(8). pp 617-629.

13. Bai Yu, Hugi Erich, Ludwig Carsten, Keller Thomas (2011). Fire performance of water-cooled GFRP columns. I: fire endurance investigation. Journal of Composites for Construction, 15(3). pp 404-412.

14. Henderson JB, Wiebelt JA, Tant MR (1985). A model for the thermal response of polymer composite materials with experimental verification. Journal of composite materials, 19(6). pp 579-595.

15. Lattimer B Y, Ouellette J (2006). Properties of composite materials for thermal analysis involving fires. Composites Part A, 37(7). pp 1068-1081.

16. Gibson AG, Wright PNH, Wu Y, Mouritz AP, Mathys Z, Gardiner CP (2003). Modelling residual mechanical properties of polymer composites after fire. Plastics, Rubber and Composites, 32(2). pp 81-90.

17. Gibson A G, Wright P N H, Wu Y S, Mouritz AP, Mathys Z, Gardiner CP (2004). The integrity of polymer composites during and after fire. Journal of composite materials, 38(15). pp 1283-1307.

18. Mouritz AP, Mathys Z(1999). Post-fire mechanical properties of marine polymer composites. Composite Structures, 47(1). pp 643-653.

19. Gibson AG, Browne TNA, Feih S, Mouritz AP (2012). Modeling composite high temperature behavior and fire response under load. Journal of composite materials, 46(16). pp 2005-2022.

20. Feih S, Mathys Z, Gibson AG, Mouritz AP (2007). Modelling the compression strength of polymer laminates in fire. Composites Part A, 38(11). pp 2354-2365.

21. Feih S, Mathys Z, Gibson AG, Mouritz AP (2007). Modelling the tension and compression strengths of polymer laminates in fire. Composites Science and Technology, 67(3). pp 551-564.
22. Feih S, Mathys Z, Gibson A G, Mouritz AP (2008). Modeling compressive skin failure of sandwich composites in fire. Journal of Sandwich Structures \& Materials, 10(3). pp 217-245.

23. Anjang A, Chevali VS, Kandare E, Mouritz AP, Feih $\mathrm{S}(2014 ;)$. Tension modelling and testing of sandwich composites in fire. Composite Structures, 113. pp 437-445. 24. Anjang A, Chevali VS, Lattimer BY, Case SW, Feih S, Mouritz AP(2015;). Post-fire mechanical properties of sandwich composite structures. Composite Structures, 132. pp 1019-1028.

25. Keller Thomas, Tracy Craig, Zhou Aixi (2006).Structural response of liquid-cooled GFRP slabs subjected to fire-Part II: Thermo-chemical and thermo-mechanical modeling. Composites Part A, 37(9). pp 1296-1308.

26. Bai Yu, Vallée Till, Keller Thomas (2007). Modeling of thermo-physical properties for FRP composites under elevated and high temperature. Composite Science and Technology, 67(15). pp 3098-3109.

27. Bai Yu, Vallée Till, Keller Thomas(2008). Modeling of thermal responses for FRP composites under elevated and high temperatures. Composite Science and Technology, 68(1). pp 47-56.

28. Bai Yu, Keller Thomas, Correia JR, Branco FA, Ferreira JG(2010). Fire protection systems for building floors made of pultruded GFRP profiles-Part 2: Modeling of thermomechanical responses. Composite Part B, 41(8). pp 630-636. 